\title{
Impact of persistence on survival of patients with breast cancer treated with endocrine therapy in Northeast China: a prospective study
}

\author{
Peng Xing ${ }^{1}$, Huiting Dong ${ }^{1}$, Qun Liu ${ }^{1}$, Fan Yao ${ }^{1}$, Yingying $\mathrm{Xu}^{1}{ }^{1}$, Bo Chen ${ }^{1}$, Xinyu \\ Zheng ${ }^{1}$, Yunfei $\mathbf{W u}^{1}$, Feng Jin ${ }^{1}$ and Jiguang $\mathbf{L i}^{1}$ \\ ${ }^{1}$ Breast Division, The First Hospital of China Medical University, Shenyang 110001, Liaoning, People's Republic of China \\ Correspondence to: Feng Jin, email: jinfeng66cn@hotmail.com
}

Keywords: breast cancer, endocrine therapy, treatment persistence, risk factors

Received: December 07, $2016 \quad$ Accepted: May 22, $2017 \quad$ Published: June 12, 2017

Copyright: Xing et al. This is an open-access article distributed under the terms of the Creative Commons Attribution License 3.0 (CC BY 3.0), which permits unrestricted use, distribution, and reproduction in any medium, provided the original author and source are credited.

\section{ABSTRACT}

The purpose of this prospective study is to investigate the impact of endocrine treatment persistence on the survival of patients with estrogen receptor-positive breast cancer treated with endocrine therapy and identify the risk factors influencing the treatment persistence. We enrolled 1085 patients from Northeast China who were diagnosed as stage I-III, estrogen receptor-positive breast cancer between January 2007 and December 2010. The prognostic factors for disease-free survival (DFS) and overall survival (OS) of patients were identified using univariate and multivariate Cox proportional hazards regression models. Multiple logistic regression analysis was done to determine the possible risk factors for non-endocrine treatment and treatment discontinuation. Among the patients enrolled, $598(55.1 \%)$ underwent 5 years of endocrine therapy, $278(25.6 \%)$ less than 5 years, and $209(19.3 \%)$ nonendocrine therapy. OS rates in the continuation, discontinuation, and non-endocrine treatment groups were $\mathbf{9 7 . 8 \%}, \mathbf{9 2 . 6 \%}$ and $74.3 \%$, and DFS $97.5 \%, 86.2 \%$ and $69.9 \%$, respectively. After adjusting for pathological and socioeconomic factors, non-endocrine therapy and discontinuation were independent predictors for DFS and OS. Elderly patients ( $\geq 65$ years), those living in suburban and rural areas, locally advanced patients, and receiving no radiotherapy and/or chemotherapy were more likely to receive non-endocrine therapy and discontinue endocrine treatment. In conclusion, the prospective study demonstrate that the persistence of endocrine treatment is low in estrogen receptor-positive breast cancer patients in Northeast China. Non-endocrine treatment and early discontinuation serve as independent prognostic factors for both DFS and OS of breast cancer patients treated with endocrine therapy.

\section{INTRODUCTION}

Breast cancer is the most common malignancy in women worldwide and the most frequent cause of cancerrelated death in females [1]. The incidence and mortality rates of breast cancer have been increasing rapidly since 1980s [2]. Endocrine therapy is an efficacious treatment option for estrogen receptor positive $(\mathrm{ER}+)$ breast cancer, which can significantly reduce the recurrence rate and mortality [3]. However, long-term of endocrine therapy is the key to ensure the efficacy. Previous study have found that 3 years or even 5 years of treatment with tamoxifen is significantly more effective than shorter tamoxifen regimens (1 year) $[4,5]$. Recently, newer statistics from two large studies, the Adjuvant Tamoxifen: Longer Against Shorter (ATLAS) trial and the Adjuvant Tamoxifen-To Offer More? (aTTom), have confirmed that longer-term tamoxifen use (for up to 10 years) rather than stopping at 5 years generates a further reduction in recurrence and mortality $[6,7]$.

Poor medication compliance and persistence is a major issue affecting all chronic diseases [8]. Breast cancer is no exception. Compliance is commonly defined as taking medication as directed (e.g., at a certain time 
of the day), whereas persistence is generally defined as continuing to take medication (correctly or incorrectly) for the recommended period. Adherence refers to the overall behavior, which includes persistence and compliance $[9,10]$. Although the benefits of endocrine therapy on $\mathrm{ER}+$ breast cancer, the adherence and persistence are rather poor [11, 12]. Van-Herk-Sukel et al. reported that about $50 \%$ of the breast cancer patients discontinued tamoxifen or any endocrine treatment before the recommended treatment period of 5 years [13]. Hershman et al. suggested that only $49 \%$ of breast cancer patients took adjuvant endocrine therapy for the full duration [14]. Early termination of endocrine therapy might increase the risk of breast cancer associated mortality [12, 15, 16]. Discontinuation of endocrine therapy is mainly due to demographic/medical variables, modifiable psychosocial characteristics, and the side effects [17-19]. However, the evidence is mainly from Western countries. The peak ages of breast cancer patients in the Western countries are mainly at 60-70 years old, which is 10 years later than the patients in the Asian countries [20, 21].

Therefore, in the present study, we aimed to investigate the persistence patterns for women patients with ER+ breast cancer receiving hormonal therapy in Northeast China. The patients were grouped according to the treatment patterns: non-endocrine treatment, discontinuation, and continuation. The effects of different patterns on patients' survival were explored, and then the underlying influence factors and reasons for non-endocrine treatment and discontinuation were tried to discover.

\section{RESULTS}

\section{Response rate}

From January 2007 to December 2010, a total of 1431 women were diagnosed with hormone receptorpositive stage I-III breast cancer at our department. We excluded patients with neoadjuvant chemotherapy (92 cases), carcinoma in situ (332 cases), disease progression during endocrine therapy (74 cases), and other malignant diseases ( 6 cases). A total of 1085 patients were enrolled in the present study. Over the 5 year follow-up period, 986 patients were successfully followed and 99 patients were lost to follow-up. The response rate was $90.8 \%$. There were respectively $7,6,10,14,13,12,10$, 11 , and 16 patients were lost from the first follow-up to the last one.

\section{Demographic and clinical characteristics of the patients}

Baseline demographic and clinical characteristics of the patients were shown in Table 1. Patients were categorized into three groups: non-endocrine treatment, early discontinuation, and continuation. The median age of the patients was 51 years (20-85 years). In total, 876 patients received endocrine therapy, i.e., 631 tamoxifen only, 183 AI only, and 62 both. Early discontinuation of endocrine therapy was noted in 278 cases $(31.7 \%)$. No statistical differences were detected with respect to the family history of breast/ovarian cancer $(P=0.670)$, history of gynecologic benign diseases $(P=0.210)$, radiotherapy status $(P=0.060)$, and median follow-up $(P=0.808)$. We observed that there were significant differences in ages $(P=0.000)$, residence $(P=0.000)$, surgery type $(P=0.000)$, tumor grade $(P=0.000)$, lymph node involvement $(P=0.000)$, and chemotherapy $(P=0.000)$ among the three groups. At the end of follow-up, 96 patients died from breast cancer and 21 patients died from non-cancer causes. Additionally, 54 patients were alive at the end of the study, but developed recurrence of the disease.

\section{Survival analysis}

The 5-year overall survival (OS) rates were 74.3\%, $92.6 \%$, and $97.8 \%$ in the non-endocrine treatment, discontinuation, and continuation groups, respectively $(P=$ 0.0058; Figure 1), whereas the 5-year disease-free survival (DFS) rates were $69.9 \%, 86.2 \%$, and $97.5 \%$, respectively $(P=0.0021$; Figure 2$)$. The predictors of OS and DFS were further analyzed by univariate and multivariate Cox proportional hazards regression (Table 2). After adjustment for clinical pathological factors and social economic factors, we confirmed that non-endocrine treatment and discontinuation still remained independent predictors for DFS (non-endocrine treatment: hazard ratio (HR), 13.180; 95\% confidence interval $(\mathrm{CI}), 7.610-22.824 ; P=0.000$; discontinuation: HR, 7.621; 95\% CI, 4.410-13.167; $P=0.000)$ and OS (non-endocrine treatment: HR, 28.080; 95\% CI, 11.017-71.571; $P=0.000$; discontinuation: HR, $10.976 ; 95 \%$ CI, 4.215-28.582; $P=0.000)$.

\section{Risk factors for non-endocrine treatment and discontinuation}

We further performed logistic regression analysis to identify the possible risk factors of non-endocrine treatment and discontinuation (Table 3). As described in the table, we observed that compared with patients who were less than 50 years old, patients more than 65 years old were one risk factor for non-endocrine therapy (odds ratio (OR), 4.204; 95\% CI, 2.268-7.792; $P=0.000)$ and discontinuation (OR, 2.179; 95\% CI, $1.074-4.420 ; P=0.031)$. Compared to patients who lived in urban area, patients who lived in suburban and rural area were risk factors for non-endocrine therapy (OR, 4.278; 95\% CI, 2.880-6.355; $P=0.000)$ and discontinuation (OR, 1.948; 95\% CI, 1.412-2.687; $P=0.000)$. Compared with patients with T1 stage, T3 stage was a risk factor for discontinuation (OR, 2.331; 95\% CI, 1.061-5.122; 
Table 1: Baseline characteristics of patients with hormone-receptor-positive breast cancer

\begin{tabular}{|c|c|c|c|c|}
\hline \multirow{2}{*}{ Characteristics, No. of patients (\%) } & \multirow{2}{*}{$\begin{array}{c}\text { Non-endocrine } \\
\text { therapy }\end{array}$} & \multicolumn{2}{|c|}{ Endocrine therapy } & \multirow{2}{*}{$P$ value } \\
\hline & & Discontinuation & Continuation & \\
\hline Ages at diagnosis, years & & & & 0.000 \\
\hline$<50$ & $69(33.0)$ & $144(51.8)$ & $281(47.0)$ & \\
\hline $50-64$ & $84(40.2)$ & $106(38.1)$ & $256(42.8)$ & \\
\hline$\geq 65$ & $56(26.8)$ & $28(10.1)$ & $61(10.2)$ & \\
\hline Residence & & & & 0.000 \\
\hline Urban & $89(42.6)$ & $156(56.1)$ & $442(73.9)$ & \\
\hline Suburban and rural & $120(57.4)$ & $122(43.9)$ & $156(26.1)$ & \\
\hline Surgery & & & & 0.000 \\
\hline Tumorectomy & $21(10.0)$ & $12(4.3)$ & $26(4.3)$ & \\
\hline Breast-conserving & $7(3.4)$ & $21(7.6)$ & $51(8.5)$ & \\
\hline Modified radical mastectomy & $181(86.6)$ & $245(88.1)$ & $521(87.2)$ & \\
\hline Family history of breast/ovarian cancer & & & & 0.670 \\
\hline Yes & $7(3.4)$ & $14(5.0)$ & $24(4.0)$ & \\
\hline No & $202(96.6)$ & $264(95.0)$ & $574(96.0)$ & \\
\hline History of gynecologic benign diseases & & & & 0.210 \\
\hline Yes & $31(14.8)$ & $39(14.0)$ & $110(18.4)$ & \\
\hline No & $178(85.2)$ & $239(86.0)$ & $488(81.6)$ & \\
\hline Tumor grade & & & & 0.000 \\
\hline $\mathrm{T} 1$ & $66(31.6)$ & $122(43.9)$ & $288(48.2)$ & \\
\hline $\mathrm{T} 2$ & $128(61.2)$ & $139(50.0)$ & $288(48.2)$ & \\
\hline $\mathrm{T} 3$ & $14(6.7)$ & $15(5.4)$ & $18(3.0)$ & \\
\hline Unknown & $1(0.5)$ & $2(0.7)$ & $4(0.6)$ & \\
\hline Lymph node & & & & 0.000 \\
\hline No & $78(37.3)$ & $150(54.0)$ & $341(57.0)$ & \\
\hline N1 & $43(20.6)$ & $66(23.7)$ & $147(24.6)$ & \\
\hline $\mathrm{N} 2$ & 37 (17.7) & $26(9.4)$ & $59(9.9)$ & \\
\hline $\mathrm{N} 3$ & $30(14.4)$ & $21(7.6)$ & $23(3.8)$ & \\
\hline Unknown & $21(10.0)$ & $15(5.3)$ & $28(4.7)$ & \\
\hline Chemotherapy & & & & 0.000 \\
\hline Yes & $104(49.8)$ & $228(82.0)$ & $465(77.8)$ & \\
\hline No & $105(50.2)$ & $50(18.0)$ & $133(22.2)$ & \\
\hline Radiotherapy & & & & 0.060 \\
\hline Yes & 38 & 68 & 158 & \\
\hline No & 171 & 210 & 440 & \\
\hline Median follow-up (months) ${ }^{*}$ & 88 & 84 & 86 & 0.808 \\
\hline
\end{tabular}

TNM, tumor node metastasis.

*Differences were analyzed using the Kruskal-Wallis test.

$P=0.035)$. Compared with patients with N0 stage, N2 stage and N3 stage were risk factors for non-endocrine therapy (N2 stage: OR, 6.614; 95\% CI, 3.200-13.671;
$P=0.000$; N3 stage: OR, $11.279 ; 95 \%$ CI, 4.826-26.362; $P=0.000$ ), and while only N3 stage was a risk factor for discontinuation (OR, 1.379; 95\% CI, 1.239-5.963; 


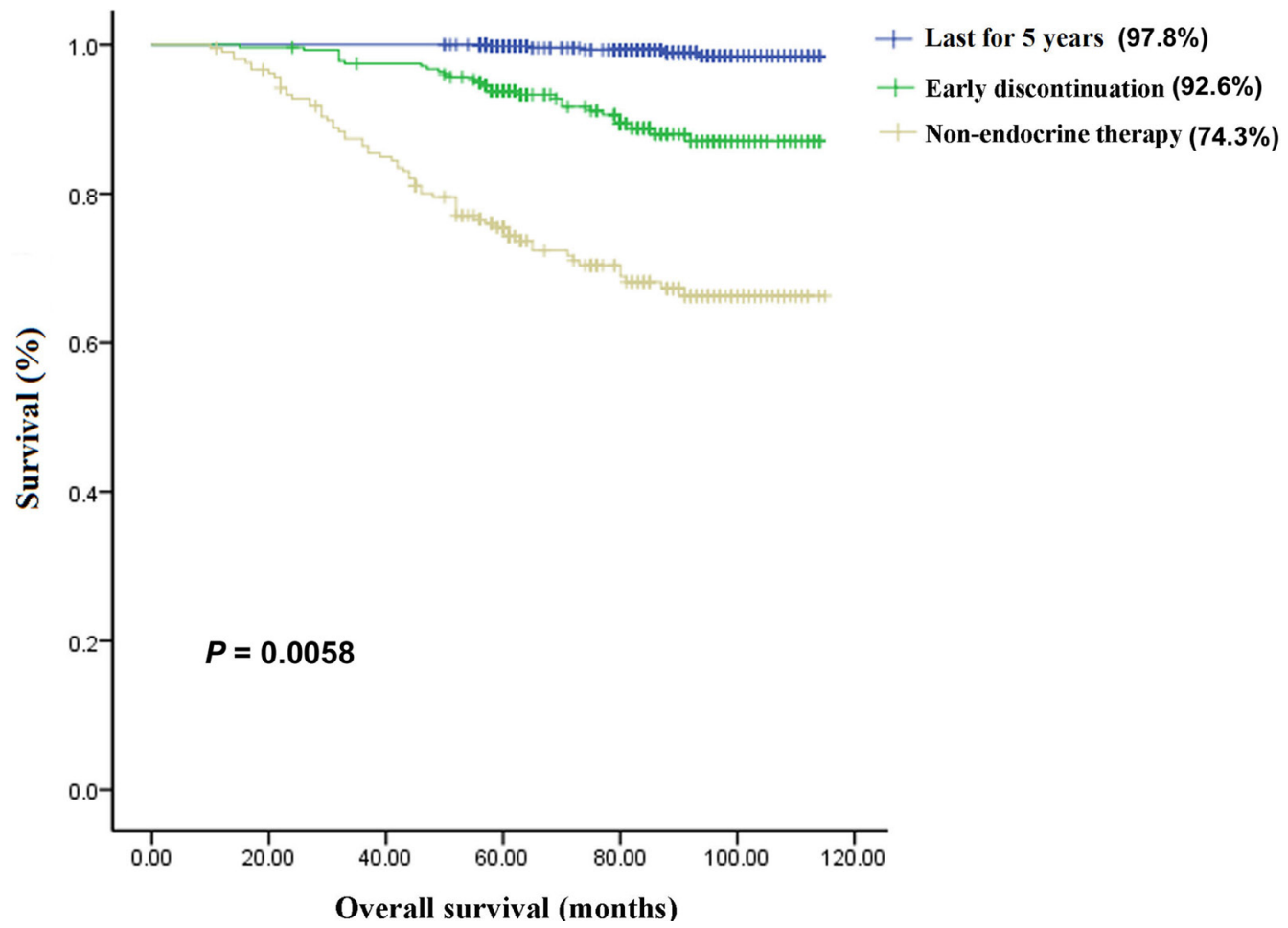

Figure 1: The 5-year overall survival (OS) rates in the three groups. The 5-year OS rates were $74.3 \%, 92.6 \%$, and $97.8 \%$, respectively, in the non-endocrine treatment $(n=209)$ group, early discontinuation $(n=278)$ group, and continuation $(n=598)$ group, and there were significant differences among the three groups.

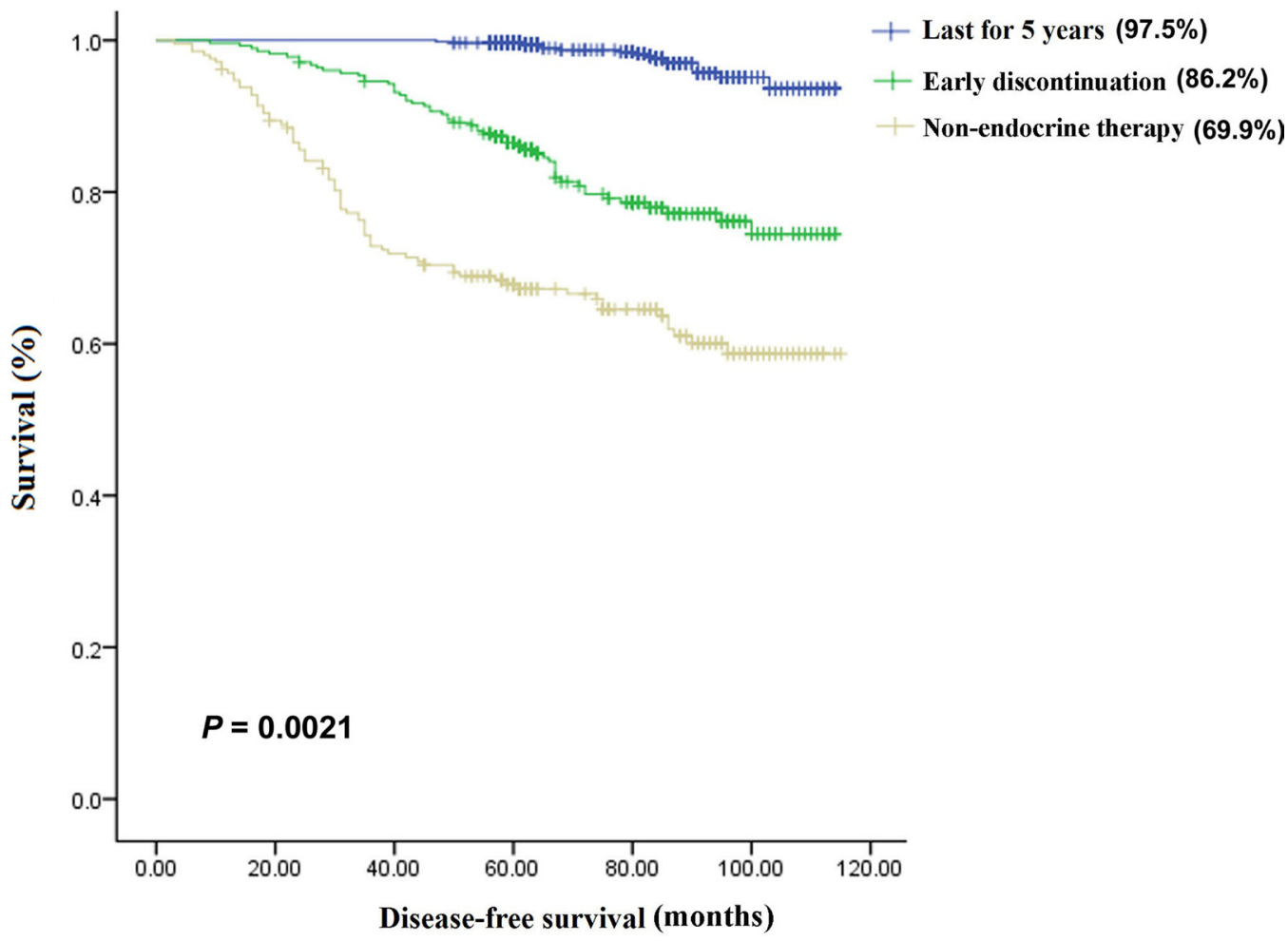

Figure 2: The 5-year disease-free survival (DFS) rates in the three groups. The 5-year DFS rates were $69.9 \%, 86.2 \%$, and $97.5 \%$, respectively, in the non-endocrine treatment $(n=209)$ group, early discontinuation $(n=278)$ group, and continuation $(n=598)$ group, and there were significant differences among the three groups. 
Table 2: Univariate and multivariate analysis of DFS and OS

\begin{tabular}{|c|c|c|c|c|c|c|c|c|}
\hline \multirow[b]{2}{*}{ Characteristics } & \multicolumn{4}{|c|}{ DFS } & \multicolumn{4}{|c|}{ os } \\
\hline & $\begin{array}{l}\text { Univariate } \\
\text { HR }(95 \% \text { CI) }\end{array}$ & $P$ value & $\begin{array}{l}\text { Multivariate } \\
\text { HR (95\% CI) }\end{array}$ & $P$ value & $\begin{array}{l}\text { Univariate } \\
\text { HR }(95 \% \text { CI) }\end{array}$ & $P$ value & $\begin{array}{l}\text { Multivariate } \\
\text { HR (95\% CI) }\end{array}$ & $P$ value \\
\hline \multicolumn{9}{|l|}{ Ages at diagnosis, years } \\
\hline$<50$ & $1.000-$ & & $1.000-$ & - & $1.000-$ & - & $1.000-$ & - \\
\hline $50-64$ & $1.105(0.779-1.567)$ & 0.575 & $1.031(0.720-1.478)$ & 0.866 & $1.073(0.692-1.663)$ & 0.754 & $0.846(0.536-1.337)$ & 0.475 \\
\hline$\geq 65$ & $1.372(0.857-2.198)$ & 0.188 & $0.823(0.477-1.420)$ & 0.484 & $1.404(0.786-2.507)$ & 0.251 & $0.621(0.319-1.210)$ & 0.161 \\
\hline \multicolumn{9}{|l|}{ Radiotherapy } \\
\hline No & $1.000-$ & - & $1.000-$ & - & $1.000-$ & - & $1.000-$ & - \\
\hline Yes & $1.73(1.235-2.421)$ & 0.001 & $0.891(0.574-1.382)$ & 0.606 & $1.602(1.048-2.449)$ & 0.03 & $0.877(0.517-1.487)$ & 0.625 \\
\hline \multicolumn{9}{|l|}{ Her-2 status } \\
\hline Negative & $1.000-$ & & $1.000-$ & - & $1.000-$ & - & $1.000-$ & - \\
\hline Positive & $1.487(1.026-2.155)$ & 0.036 & $1.420(0.965-2.090)$ & 0.075 & $1.342(0.834-2.161)$ & 0.23 & $1.302(0.792-2.141)$ & 0.299 \\
\hline \multicolumn{9}{|l|}{ Surgery } \\
\hline Tumorectomy & $1.000-$ & - & $1.000-$ & - & $1.000-$ & - & $1.000-$ & - \\
\hline Breast-conserving & $0.532(0.198-1.429)$ & 0.211 & $0.161(0.035-0.752)$ & 0.020 & $0.348(0.087-1.390)$ & 0.135 & $0.11(0.017-0.700)$ & 0.019 \\
\hline $\mathrm{MRD} /$ Total mastectomy+SLN & $0.847(0.432-1.665)$ & 0.631 & $0.114(0.029-0.448)$ & 0.002 & $0.838(0.366-1.916)$ & 0.675 & $0.099(0.022-0.446)$ & 0.003 \\
\hline \multicolumn{9}{|l|}{ T stage } \\
\hline $\mathrm{T} 1$ & $1.000-$ & - & $1.000-$ & - & $1.000-$ & - & $1.000-$ & - \\
\hline $\mathrm{T} 2$ & $3.272(2.181-4.907)$ & 0.000 & $1.953(1.259-3.028)$ & 0.003 & $5.985(3.175-11.281)$ & 0.000 & $2.946(1.488-5.833)$ & 0.002 \\
\hline $\mathrm{T} 3$ & $5.075(2.647-9.732)$ & 0.000 & $2.237(1.119-4.471)$ & 0.023 & $11.08(4.803-25.560)$ & 0.000 & $3.545(1.463-8.592)$ & 0.005 \\
\hline Unknown & $2.542(0.347-18.644)$ & 0.359 & $3.016(0.404-22.522)$ & 0.282 & $6.81(0.879-52.765)$ & 0.066 & $3.786(0.457-31.371)$ & 0.217 \\
\hline \multicolumn{9}{|l|}{$\mathrm{N}$ stage } \\
\hline N0 & $1.000-$ & - & $1.000-$ & - & $1.000-$ & - & $1.000-$ & - \\
\hline N1 & $1.598(0.988-2.584)$ & 0.056 & $1.470(0.904-2.390)$ & 0.120 & $1.953(0.984-3.876)$ & 0.056 & $1.735(0.870-3.461)$ & 0.118 \\
\hline $\mathrm{N} 2$ & $4.57(2.900-7.203)$ & 0.000 & $3.732(2.196-6.344)$ & 0.000 & $7.064(3.833-13.019)$ & 0.000 & $4.938(2.493-9.781)$ & 0.000 \\
\hline N3 & $12.046(7.775-18.663)$ & 0.000 & $7.386(4.384-12.444)$ & 0.000 & $22.027(12.447-38.980)$ & 0.000 & $9.605(5.052-18.259)$ & 0.000 \\
\hline Unknown & $1.713(0.768-3.819)$ & 0.188 & $0.195(0.039-0.985)$ & 0.048 & $2.204(0.746-6.514)$ & 0.153 & $0.166(0.025-1.117)$ & 0.065 \\
\hline \multicolumn{9}{|l|}{ Chemotherapy } \\
\hline No & $1.000-$ & - & $1.000-$ & - & $1.000-$ & - & $1.000-$ & - \\
\hline Yes & $0.714(0.506-1.006)$ & 0.054 & $1.033(0.677-1.578)$ & 0.880 & $0.512(0.340-0.771)$ & 0.001 & $0.758(0.458-1.253)$ & 0.280 \\
\hline \multicolumn{9}{|l|}{ Endocrine therapy } \\
\hline Non-endocrine treatment & $16.864(9.970-28.526)$ & 0.000 & $13.180(7.610-22.824)$ & 0.000 & $44.144(17.742-109.686)$ & 0.000 & $28.080(11.017-71.571)$ & 0.000 \\
\hline Discontinuation & $7.824(4.546-13.465)$ & 0.000 & $7.621(4.410-13.167)$ & 0.000 & $12.696(4.902-32.880)$ & 0.000 & $10.976(4.215-28.582)$ & 0.000 \\
\hline Continuation & $1.000-$ & - & $1.000-$ & - & $1.000-$ & - & $1.000-$ & - \\
\hline
\end{tabular}

HR, hazard rate; CI, confidence interval; AI, aromatase inhibitors; MRD, modified radical mastectomy; SLN, sentinel lymph node biopsy.

$P=0.013)$. Moreover, the results showed that patients who did not received radiotherapy and/or chemotherapy were risk factors for non-endocrine therapy (no radiotherapy: OR, 4.723; 95\% $\mathrm{CI}, 2.479-8.998 ; P=0.000$; no chemotherapy: OR, 2.065; 95\% CI, 1.350-3.160; $P=0.001$ ) and discontinuation (no radiotherapy: OR, $1.753 ; 95 \%$ CI, $1.032-2.977 ; P=0.038$; no chemotherapy: OR, $1.602 ; 95 \% \mathrm{CI}, 1.048-2.448$;
$P=0.030$ ). Interestingly, we observed that the types of endocrine therapy were also related with discontinuation. Tamoxifen only was a risk factor for discontinuation (OR, 2.351; 95\% CI, 1.450-3.812; $P=0.001$ ). However, type of surgery, family history of breast/ovarian cancer, and history of gynecologic benign diseases had no significant association with the non-endocrine therapy and discontinuation. 
Table 3: Logistic regression analysis of risk factors associated with non-endocrine treatment and early discontinuation

\begin{tabular}{|c|c|c|c|c|}
\hline Characteristics & Non-endocrine treatment & & Discontinuation & \\
\hline & OR $(95 \% C I)$ & $P$ value & OR $(95 \% \mathrm{CI})$ & $P$ value \\
\hline \multicolumn{5}{|l|}{ Ages at diagnosis, years } \\
\hline$<50$ & $1.000-$ & - & $1.000-$ & - \\
\hline $50-64$ & $1.408(0.926-2.142)$ & 0.109 & $1.14(0.813-1.599)$ & 0.448 \\
\hline$\geq 65$ & $4.204(2.268-7.792)$ & 0.000 & $2.179(1.074-4.420)$ & 0.031 \\
\hline \multicolumn{5}{|l|}{ Residence } \\
\hline Urban & - & & $1.000-$ & - \\
\hline Suburban and rural & $4.278(2.880-6.355)$ & 0.000 & $1.948(1.412-2.687)$ & 0.000 \\
\hline \multicolumn{5}{|l|}{ Surgery } \\
\hline Tumorectomy & $1.064(0.110-10.318)$ & 0.957 & $0.612(0.127-2.943)$ & 0.540 \\
\hline Breast-conserving & $1.505(0.575-3.934)$ & 0.405 & $1.286(0.674-2.453)$ & 0.445 \\
\hline Modified radical mastectomy & - & - & $1.000-$ & - \\
\hline \multicolumn{5}{|l|}{$\begin{array}{l}\text { Family history of breast/ovarian } \\
\text { cancer }\end{array}$} \\
\hline Yes & $1.800(0.659-4.911)$ & 0.251 & $1.526(0.756-3.081)$ & 0.238 \\
\hline No & - & - & $1.000-$ & - \\
\hline \multicolumn{5}{|l|}{$\begin{array}{l}\text { History of gynecologic benign } \\
\text { diseases }\end{array}$} \\
\hline Yes & $1.307(0.785-2.175)$ & 0.304 & $0.861(0.568-1.305)$ & 0.481 \\
\hline No & - & & $1.000-$ & - \\
\hline \multicolumn{5}{|l|}{ T stage } \\
\hline $\mathrm{T} 1$ & - & & $1.000-$ & - \\
\hline $\mathrm{T} 2$ & $1.400(0.940-2.085)$ & 0.098 & $1.065(0.777-1.459)$ & 0.695 \\
\hline $\mathrm{T} 3$ & $1.963(0.706-5.462)$ & 0.196 & $2.331(1.061-5.122)$ & 0.035 \\
\hline Unknown & $0.675(0.053-8.625)$ & 0.763 & $0.857(0.146-5.045)$ & 0.865 \\
\hline \multicolumn{5}{|l|}{$\mathrm{N}$ stage } \\
\hline N0 & - & - & $1.000-$ & - \\
\hline N1 & $1.288(0.804-2.064)$ & 0.293 & $0.991(0.684-1.436)$ & 0.961 \\
\hline N2 & $6.614(3.200-13.671)$ & 0.000 & $1.379(0.709-2.682)$ & 0.344 \\
\hline N3 & $11.279(4.826-26.362)$ & 0.000 & $1.379(1.239-5.963)$ & 0.013 \\
\hline Unknown & $2.123(0.208-21.637)$ & 0.525 & $1.379(0.652-11.806)$ & 0.167 \\
\hline \multicolumn{5}{|l|}{ Radiotherapy } \\
\hline Yes & - & - & $1.000-$ & - \\
\hline No & $4.723(2.479-8.998)$ & 0.000 & $1.753(1.032-2.977)$ & 0.038 \\
\hline \multicolumn{5}{|l|}{ Chemotherapy } \\
\hline Yes & - & - & $1.000-$ & - \\
\hline No & $2.065(1.350-3.160)$ & 0.001 & $1.602(1.048-2.448)$ & 0.030 \\
\hline \multicolumn{5}{|l|}{ Types of endocrine therapy } \\
\hline Tamoxifen only & - & - & $2.351(1.450-3.812)$ & 0.001 \\
\hline AI only & - & - & $1.000-$ & - \\
\hline Tamoxifen+ AI & - & - & $0.970 .419-2.249)$ & 0.944 \\
\hline
\end{tabular}

OR, odds ratio; CI, confidence interval; AI, aromatase inhibitors. 


\section{Reasons for patients not receiving endocrine therapy}

Among the 1085 patients, there were 209 patients who had not received endocrine therapy. The common reasons were listed as follows (Table 4): (a) no confidence in endocrine therapy $(n=132)$; (b) advanced age or accompanied by other cardiovascular and cerebrovascular disease $(n=50)$; (c) fearing of side effects caused by endocrine therapy $(n=12)$; (d) switching to traditional Chinese medicine $(n=8)$; and (e) economic or other causes $(n=7)$.

\section{Reasons for early discontinuation of endocrine therapy}

There were a total of 278 patients who early discontinued the endocrine therapy. The percentages of patients who continued endocrine therapy were respectively $93.2 \%, 86.2 \%, 78.8 \%, 72.3 \%$, and $68.3 \%$ from the first year to the fifth year. The reasons were listed as below (Table 5): (a) presence of side effects $(n=134)$ including endometrial thickening $(n=48)$, facial flush, sweat, and weakness $(n=23)$, and gastrointestinal discomfort and limb ache $(n=63)$; (b) feeling no need to continue treatment due to good outcome $(n=122)$; (c) patients with advanced ages or accompanied by other cardiovascular and cerebrovascular disease $(n=12)$; (d) switching to traditional Chinese medicine $(n=5)$; and (e) economic or other causes $(n=5)$.

\section{DISCUSSION}

Endocrine therapy has been identified as an effective treatment for ER+ breast cancer, with a recommended standard time for at least 5 years. Nevertheless, the compliance and persistence to medications is rather poor. In the prospective study, we confirmed that the persistence of endocrine treatment was also poor in women patients with ER+ breast cancer in Northeast China. Non-endocrine treatment and early discontinuation were independent predictors for both DFS and OS. Elderly women, patients who lived in suburban and rural areas, locally advanced patients, and patients who received no radiotherapy and/or chemotherapy were significantly detected in patients with non-endocrine treatment and early discontinuation.

It has been well documented that surgery followed by adjuvant treatment is a gold standard for breast cancer treatment [22]. Approximately $80 \%$ of breast cancers are ER+ and thus endocrine therapy is regarded as an important complement to surgery in the majority of patients [23]. Currently endocrine therapy includes gonadotropin-releasing hormone agonists (GnRHa), selective estrogen receptor modulators (SERMs) or downregulators (SERDs), and aromatase inhibitors (AIs), or a combination [23]. Although the benefits of receiving endocrine therapy, a growing body of evidence suggest that discontinuation of endocrine therapy has a negative impact on recurrence and mortality of breast cancer $[14,15,24]$. For example, a recent study has shown that the earlier termination of chemotherapy, the higher risk of breast cancer related death [14]. However, the available evidence suggested that only $30 \%$ to $50 \%$ of women were fully complete with hormonal therapy for 5 years [25-32]. In our study, the discontinuation rate was $55.1 \%$, which was a little higher than the previous above studies. A possible explanation for this phenomenon was the response and/or self-presentation bias. Some reliable data might not be able to directly access from patents because of these biases. In spite of this, improving of the follow-up quality may reduce the biases in our study. Although the relatively persistence rate at the beginning of the endocrine therapy in our study, the rate decreased year by year from $93.2 \%$ in the first year to $68.2 \%$ in the fifth year. Our results were in line with previous studies $[25,27,33]$ showing that about $7-10 \%$ patients discontinued hormonal therapy (either tamoxifen or AI) every year. In addition, our data also revealed that non-endocrine therapy and early discontinuation were independent $r$ predictors of breast cancer related death, which were consistent with previous studies [12, 15, 34].

We further analyzed the potential risk factors of nonendocrine treatment and discontinuation by univariate and multivariate Cox proportional hazards regression models. Among all the risk factors, the ages of patients appeared to be very important. No significant difference was found in the persistence of among younger patients ( $<50$ years) and patients who were $50-65$ years old. But interestingly, we observed that the elderly patients were one of the risk factors of non-endocrine therapy and discontinuation. Our results were similar with previous studies concerning the ages $[35,36]$. While our findings were partly consistence with Sheppard and colleagues [29], in which the authors observed that Swedish patients younger than 40 and older than 65 are at a higher risk of treatment discontinuation. However, Hershman et al. reported that the adherence was rather poor among younger women [14]. Moreover, a recent published paper by Fan et al. also suggested that young age was identified as a risk factor for nonadherence in Taiwanese women treated with hormone therapy [37]. The poor adherence and persistence in the younger patients is mainly due to the side effects caused by endocrine therapy [38-40]. The age difference between our study and the above two studies might be explained as follows: first, we enrolled large proportions of young patients at diagnosis $<50$ years $(45.5 \%$ of all patients); second, Northeast of China is relatively underdeveloped compared to Western countries or even Taiwan. Lack of medical and public health infrastructure in these areas is still a challenge for communities, especially for the elderly; third, elderly women more often display less fear of cancer recurrence and health worry [41], especially in 
Table 4: Reasons for patients not receiving endocrine therapy

\begin{tabular}{lc}
\hline Reasons & No. (\%) \\
\hline Patients had no confidence in endocrine therapy & $132(63.16)$ \\
Patients with advanced age or accompanied by other cardiovascular and cerebrovascular disease & $50(23.92)$ \\
Patients were fear of side effects caused by endocrine therapy & $12(5.74)$ \\
Patients did not trust the endocrine therapy but turned to Traditional Chinese Medicine & $8(3.83)$ \\
Patients could not afford or were not easily obtain the drugs due to the financial or residential conditions & $7(3.35)$ \\
\hline
\end{tabular}

Table 5: Reasons for patient's early discontinuing endocrine therapy

\begin{tabular}{lc}
\hline Reasons & No. (\%) \\
\hline Patients presented side effects & $134(48.20)$ \\
Endometrial thickening & $48(17.27)$ \\
Facial flush, Sweat, and Weakness & $23(8.27)$ \\
Gastrointestinal discomfort and Limb ache & $63(22.66)$ \\
Patients felt well and thought no need to continue the endocrine therapy & $122(43.88)$ \\
Patients with advanced ages or accompanied by other cardiovascular and cerebrovascular disease & $12(4.32)$ \\
Patients turned to Traditional Chinese Medicine & $5(1.80)$ \\
Patients could not afford or were not easily obtain the drugs due to the financial or residential conditions & $5(1.80)$ \\
\hline
\end{tabular}

the undeveloped areas; and fourth, elderly patients are at greater risk of developing medical comorbidities (e.g. hypertension, heart disease, and/or diabetes) and cognitive impairment, therefore elderly individual are using many drugs at the same time [42]. Increasing forgetfulness, confusion, lack of understanding of treatment, and suspicions of drugs can all contribute to the failure of maintaining drug regimens [43].

Moreover, we observed that residence place influenced the endocrine treatment patterns. Shenyang is the largest city in Northeast China, however, a total of 398 patients were from suburban and rural. Patients in the suburban and rural areas may have less opportunity acquiring higher education level and are inconvenient and inadequate to visit hospitals and/or to obtain medication due to the financial problems. As mentioned in our findings, we found that patient-related factors (such as the negative attitudes, perceptions, expectations and beliefs) appeared to be critical for not initiation of endocrine treatment or discontinuation, which were in line with previous studies [44-46]. In addition, we also demonstrated that therapy-related factors (such as side effects) contributed to the non-endocrine treatment and/ or discontinuation of endocrine therapy. Compared to AI only or sequentially combined with tamoxifen, tamoxifen only was a risk factor for discontinuation in the present study. Although tamoxifen is well tolerated in patients, significant and different side effects may occur during the long-term therapy, leading to the poor adherence and persistence $[47,48]$. A growing number of studies have pointed out that the side effects of tamoxifen are the main cause of the low adherence $[47,49,50]$. AI has been identified to be superior to tamoxifen as hormonal therapy for postmenopausal ER+ breast cancer [51]. More interestingly, the results in the present study showed that the persistence was also lower in patients with locally advanced stage and patients without radiotherapy and/or chemotherapy. For patients with locally advanced stage, patients easily lost confidence due to the lack of education and the perception that endocrine therapy can bring much benefit. Endocrine therapy is normally performed postchemotherapy or post-radiotherapy. For patients who received no radiotherapy and/or chemotherapy or who cannot tolerate the treatments due to the side effects, the patient's general condition were very poor and they seemed not to take a long time of endocrine therapy.

A main limitation of our study was the self-reported information from the patients. Northeast China is a relatively backward region, and we were still unable to get medication information through the medical system network. The medication information was only obtained by telephone follow-up, outpatient follow-up, and medical education conference. Although the limitation, our results indicate that the persistence of adjuvant endocrine therapy is low in women breast cancer patients in Northeast China. Non-endocrine therapy and early discontinuation serves as independent predictors for DFS and OS. Elderly women, those who live in suburban and rural areas, patients with locally advanced stage, and patients without radiotherapy and chemotherapy treatment are at high risk of non- 
endocrine treatment and discontinuation of endocrine treatment.

\section{MATERIALS AND METHODS}

\section{Subjects and information collection}

We enrolled a cohort of women who were diagnosed with breast cancer between January 2007 and December 2010 at the First Hospital of China Medical University (Shenyang, China). Demographic and clinic pathological parameters including age at diagnosis, family history of breast/ovarian cancer, history of gynecological diseases, tumor stage, lymph node metastasis involvement, types of surgery, and therapeutic modality were retrieved from patient records. Tumor stage was used to evaluate the tumor size $(\mathrm{T} 1: \leq 2 \mathrm{~cm}, \mathrm{~T} 2:>2 \mathrm{~cm}$ but $\leq 5 \mathrm{~cm}$, and T3: $>5 \mathrm{~cm}$ ). Types of surgery included tumorectomy, breastconserving, and modified radical mastectomy/mastectomy plus sentinel lymph node biopsy. Endocrine therapy consisted of tamoxifen only, aromatase inhibitor (AI) only, or both. This study was approved by the Ethics Committee of our hospital, and written informed consent was obtained from each participant.

\section{Follow-up and definitions}

Telephone follow-up was conducted at 6-month intervals for 5 years by experienced interviewers. The information included anticancer treatment after discharge and survival status. The reasons for non-endocrine treatment or early discontinuation were collected. Information on disease progression was extracted from outpatient followup records. The follow-up deadline was August 2016. Median follow-up time was 61 months, and the mean number of follow-up for each patient is 3.4 times. To avoid the potential the rate of lost to follow-up, a continuing medical education conference was held every six month in our hospital. Herein, continuation is defined as receiving endocrine treatment for 5 years. Early discontinuation is defined as cessation of tamoxifen and/or AI treatment within 5 years. DFS is defined as the time between diagnosis of disease and recurrence or distant metastasis. DFS was identified by clinical evidence of disease and the pathological examination (eg, punch biopsy). OS is defined as the time from diagnosis of disease to death.

\section{Statistical analysis}

Kaplan-Meier curves were used to quantify the values of DFS and OS over time and compared using the log-rank test. Univariate and multivariate Cox proportional hazards regression models were performed to identify prognostic factors for DFS and OS of patients. Multiple logistic regression analysis was conducted to determine the possible risk factors for non-endocrine treatment and treatment discontinuation. All analyses were conducted using SPSS version 18 (SPSS Inc., Chicago, IL). A value of $P<0.05$ was considered as significant difference.

\section{Abbreviations}

ER+, Estrogen receptor positive; ATLAS, Adjuvant Tamoxifen: Longer Against Shorter; aTTom trial and the Adjuvant Tamoxifen-To Offer More?; AI, aromatase inhibitor; DFS, disease-free survival; OS, overall survival; GnRHa, gonadotropin-releasing hormone agonists; SERMs, selective estrogen receptor modulators; SERDs, selective estrogen receptor own-regulators; HR, hazard rate; $\mathrm{CI}$, confidence interval; MRD, modified radical mastectomy; SLN, sentinel lymph node biopsy.

\section{Authors' contributions}

PX developed the project and wrote the first draft of the manuscript. The final draft of the manuscript was written by PX, JGLi and FJ with comments from all authors. All authors participated in the interpretation and discussion of data.

\section{ACKNOWLEDGMENTS}

The authors would like to thank doctors, nurses, patients and their family members for their kindness to support our study.

\section{CONFLICTS OF INTEREST}

The authors declare that they have no conflict of interest.

\section{REFERENCES}

1. Jemal A, Bray F, Center MM, Ferlay J, Ward E, Forman D. Global cancer statistics. CA Cancer J Clin. 2011; 61:69-90. https://doi.org/10.3322/caac.20107.

2. Li T, Mello-Thoms C, Brennan PC. Descriptive epidemiology of breast cancer in China: incidence, mortality, survival and prevalence. Breast Cancer Res Treat. 2016; 159:395-406. https://doi.org/10.1007/s10549-0163947-0.

3. Early Breast Cancer Trialists' Collaborative Group (EBCTCG). Effects of chemotherapy and hormonal therapy for early breast cancer on recurrence and 15-year survival: an overview of the randomised trials. Lancet. 2005; 365:1687-717. https://doi.org/10.1016/S01406736(05)66544-0.

4. Early Breast Cancer Trialists' Collaborative Group. Systemic treatment of early breast cancer by hormonal, cytotoxic, or immune therapy: 133 randomised trials 
involving 31000 recurrences and 24000 deaths among 75000 women. Lancet. 1992; 339: 1-15. https://doi. org/10.1016/0140-6736(92)90139-T.

5. Bryant J, Fisher B, Dignam J. Duration of adjuvant tamoxifen therapy. J Natl Cancer Inst Monogr. 2001; 2001:56-61. https://doi.org/10.1093/oxfordjournals. jncimonographs.a003462.

6. Davies C, Pan H, Godwin J, Gray R, Arriagada R, Raina V, Abraham M, Medeiros Alencar VH, Badran A, Bonfill X, Bradbury J, Clarke M, Collins R, et al, and Adjuvant Tamoxifen: Longer Against Shorter (ATLAS) Collaborative Group. Long-term effects of continuing adjuvant tamoxifen to 10 years versus stopping at 5 years after diagnosis of oestrogen receptor-positive breast cancer: ATLAS, a randomised trial. Lancet. 2013; 381:805-16. https://doi. org/10.1016/S0140-6736(12)61963-1.

7. Gray RG, Rea D, Handley K, Bowden SJ, Perry P, Earl HM, Poole CJ, Bates T, Shan C, Dewar JA, Fernando IN, Grieve $\mathrm{R}$, Nicoll J, et al. aTTom: long-term effects of continuing adjuvant tamoxifen to 10 years versus stopping at 5 years in 6,953 women with early breast cancer. J Clin Oncol. 2013; 31:2631-32. https://doi.org/10.1200/jco.2013.31.18_suppl.5.

8. De Geest S, Sabaté E. Adherence to long-term therapies: evidence for action. Eur J Cardiovasc Nurs. 2003; 2:323. https://doi.org/10.1016/S1474-5151(03)00091-4.

9. Andrade SE, Kahler KH, Frech F, Chan KA. Methods for evaluation of medication adherence and persistence using automated databases. Pharmacoepidemiol Drug Saf. 2006; 15:565-74. https://doi.org/10.1002/pds.1230.

10. Dezii CM. Persistence with drug therapy: a practical approach using administrative claims data. Manag Care. 2001; 10:42-45.

11. Font R, Espinas JA, Gil-Gil M, Barnadas A, Ojeda B, Tusquets I, Segui MA, Margelí M, Arcusa A, Prat A, Garcia M, Borras JM. Prescription refill, patient self-report and physician report in assessing adherence to oral endocrine therapy in early breast cancer patients: a retrospective cohort study in Catalonia, Spain. Br J Cancer. 2012; 107:1249-56. https://doi.org/10.1038/bjc.2012.389.

12. Hershman DL, Shao T, Kushi LH, Buono D, Tsai WY, Fehrenbacher L, Kwan M, Gomez SL, Neugut AI. Early discontinuation and non-adherence to adjuvant hormonal therapy are associated with increased mortality in women with breast cancer. Breast Cancer Res Treat. 2011; 126:52937. https://doi.org/10.1007/s10549-010-1132-4.

13. van Herk-Sukel MP, van de Poll-Franse LV, Voogd AC, Nieuwenhuijzen GA, Coebergh JW, Herings RM. Half of breast cancer patients discontinue tamoxifen and any endocrine treatment before the end of the recommended treatment period of 5 years: a population-based analysis. Breast Cancer Res Treat. 2010; 122:843-51. https://doi. org/10.1007/s10549-009-0724-3.

14. Hershman DL, Kushi LH, Shao T, Buono D, Kershenbaum A, Tsai WY, Fehrenbacher L, Gomez SL, Miles S, Neugut
AI. Early discontinuation and nonadherence to adjuvant hormonal therapy in a cohort of 8,769 early-stage breast cancer patients. J Clin Oncol. 2010; 28:4120-28. https://doi. org/10.1200/JCO.2009.25.9655.

15. Makubate B, Donnan PT, Dewar JA, Thompson AM, McCowan C. Cohort study of adherence to adjuvant endocrine therapy, breast cancer recurrence and mortality. Br J Cancer. 2013; 108:1515-24. https://doi.org/10.1038/bjc.2013.116.

16. Ma AM, Barone J, Wallis AE, Wu NJ, Garcia LB, Estabrook A, Rosenbaum-Smith SM, Tartter PI. Noncompliance with adjuvant radiation, chemotherapy, or hormonal therapy in breast cancer patients. Am J Surg. 2008; 196:500-04. https://doi.org/10.1016/j.amjsurg.2008.06.027.

17. Stanton AL, Petrie KJ, Partridge AH. Contributors to nonadherence and nonpersistence with endocrine therapy in breast cancer survivors recruited from an online research registry. Breast Cancer Res Treat. 2014; 145:525-34. https://doi.org/10.1007/s10549-014-2961-3.

18. Verbrugghe M, Verhaeghe S, Lauwaert K, Beeckman D, Van Hecke A. Determinants and associated factors influencing medication adherence and persistence to oral anticancer drugs: a systematic review. Cancer Treat Rev. 2013; 39:610-21. https://doi.org/10.1016/j.ctrv.2012.12.014.

19. Partridge AH, LaFountain A, Mayer E, Taylor BS, Winer E, Asnis-Alibozek A. Adherence to initial adjuvant anastrozole therapy among women with early-stage breast cancer. J Clin Oncol. 2008; 26:556-62. https://doi.org/10.1200/ JCO.2007.11.5451.

20. Leong SP, Shen ZZ, Liu TJ, Agarwal G, Tajima T, Paik NS, Sandelin K, Derossis A, Cody H, Foulkes WD. Is breast cancer the same disease in Asian and Western countries? World J Surg. 2010; 34:2308-24. https://doi.org/10.1007/ s00268-010-0683-1.

21. Song QK, Li J, Huang R, Fan JH, Zheng RS, Zhang BN, Zhang B, Tang ZH, Xie XM, Yang HJ, He JJ, Li H, Li JY, et al. Age of diagnosis of breast cancer in china: almost 10 years earlier than in the United States and the European union. Asian Pac J Cancer Prev. 2014; 15:10021-25. https:// doi.org/10.7314/APJCP.2014.15.22.10021.

22. Miller E, Lee HJ, Lulla A, Hernandez L, Gokare P, Lim B. Current treatment of early breast cancer: adjuvant and neoadjuvant therapy. F1000Res. 2014; 3:198. https://doi. org/10.12688/f1000research.4340.1.

23. Lumachi F, Santeufemia DA, Basso SM. Current medical treatment of estrogen receptor-positive breast cancer. World J Biol Chem. 2015; 6:231-39. https://doi.org/10.4331/wjbc. v6.i3.231.

24. Neugut AI, Hillyer GC, Kushi LH, Lamerato L, Buono DL, Nathanson SD, Bovbjerg DH, Mandelblatt JS, Tsai WY, Jacobson JS, Hershman DL. A prospective cohort study of early discontinuation of adjuvant chemotherapy in women with breast cancer: the breast cancer quality of care study (BQUAL). Breast Cancer Res Treat. 2016; 158:127-38. https://doi.org/10.1007/s10549-016-3855-3. 
25. Kimmick G, Anderson R, Camacho F, Bhosle M, Hwang W, Balkrishnan R. Adjuvant hormonal therapy use among insured, low-income women with breast cancer. J Clin Oncol. 2009; 27:3445-51. https://doi.org/10.1200/ JCO.2008.19.2419.

26. Partridge AH, Archer L, Kornblith AB, Gralow J, Grenier D, Perez E, Wolff AC, Wang X, Kastrissios H, Berry D, Hudis C, Winer E, Muss H. Adherence and persistence with oral adjuvant chemotherapy in older women with early-stage breast cancer in CALGB 49907: adherence companion study 60104. J Clin Oncol. 2010; 28:2418-22. https://doi.org/10.1200/JCO.2009.26.4671.

27. Ziller V, Kalder M, Albert US, Holzhauer W, Ziller M, Wagner U, Hadji P. Adherence to adjuvant endocrine therapy in postmenopausal women with breast cancer. Ann Oncol. 2009; 20:431-36. https://doi.org/10.1093/annonc/ mdn646.

28. Tan X, Marshall VD, Anderson RT, Donohoe J, Camacho F, Balkrishnan R. Adjuvant therapy use among Appalachian breast cancer survivors. Medicine (Baltimore). 2015; 94:e1071. https://doi.org/10.1097/MD.0000000000001071.

29. Sheppard VB, Faul LA, Luta G, Clapp JD, Yung RL, Wang JH, Kimmick G, Isaacs C, Tallarico M, Barry WT, Pitcher BN, Hudis C, Winer EP, et al. Frailty and adherence to adjuvant hormonal therapy in older women with breast cancer: CALGB protocol 369901. J Clin Oncol. 2014; 32:2318-27. https://doi.org/10.1200/JCO.2013.51.7367.

30. Wigertz A, Ahlgren J, Holmqvist M, Fornander T, Adolfsson J, Lindman H, Bergkvist L, Lambe M. Adherence and discontinuation of adjuvant hormonal therapy in breast cancer patients: a population-based study. Breast Cancer Res Treat. 2012; 133:367-73. https://doi.org/10.1007/ s10549-012-1961-4.

31. Kidwell KM, Harte SE, Hayes DF, Storniolo AM, Carpenter J, Flockhart DA, Stearns V, Clauw DJ, Williams DA, Henry NL. Patient-reported symptoms and discontinuation of adjuvant aromatase inhibitor therapy. Cancer. 2014; 120:2403-11. https://doi.org/10.1002/cncr.28756.

32. Chlebowski RT, Kim J, Haque R. Adherence to endocrine therapy in breast cancer adjuvant and prevention settings. Cancer Prev Res (Phila). 2014; 7:378-87. https://doi. org/10.1158/1940-6207.CAPR-13-0389.

33. Murphy CC, Bartholomew LK, Carpentier MY, Bluethmann SM, Vernon SW. Adherence to adjuvant hormonal therapy among breast cancer survivors in clinical practice: a systematic review. Breast Cancer Res Treat. 2012; 134:45978. https://doi.org/10.1007/s10549-012-2114-5.

34. Yood MU, Owusu C, Buist DS, Geiger AM, Field TS, Thwin SS, Lash TL, Prout MN, Wei F, Quinn VP, Frost FJ, Silliman RA. Mortality impact of less-thanstandard therapy in older breast cancer patients. J Am Coll Surg. 2008; 206:66-75. https://doi.org/10.1016/j. jamcollsurg.2007.07.015.

35. Barron TI, Connolly R, Bennett K, Feely J, Kennedy MJ. Early discontinuation of tamoxifen: a lesson for oncologists.
Cancer. 2007; 109:832-39. https://doi.org/10.1002/ cncr.22485.

36. Partridge AH, Wang PS, Winer EP, Avorn J. Nonadherence to adjuvant tamoxifen therapy in women with primary breast cancer. J Clin Oncol. 2003; 21:602-06. https://doi. org/10.1200/JCO.2003.07.071.

37. Hsieh KP, Chen LC, Cheung KL, Yang YH. Risks of nonadherence to hormone therapy in Asian women with breast cancer. Kaohsiung J Med Sci. 2015; 31:328-34. https://doi.org/10.1016/j.kjms.2015.04.002.

38. Compas BE, Stoll MF, Thomsen AH, Oppedisano G, Epping-Jordan JE, Krag DN. Adjustment to breast cancer: age-related differences in coping and emotional distress. Breast Cancer Res Treat. 1999; 54:195-203. https://doi. org/10.1023/A:1006164928474.

39. Bleyer A. Young adult oncology: the patients and their survival challenges. CA Cancer J Clin. 2007; 57:242-55. https://doi.org/10.3322/canjclin.57.4.242.

40. Pellegrini I, Sarradon-Eck A, Soussan PB, Lacour AC, Largillier R, Tallet A, Tarpin C, Julian-Reynier C. Women's perceptions and experience of adjuvant tamoxifen therapy account for their adherence: breast cancer patients' point of view. Psychooncology. 2010; 19:472-79. https://doi. org/10.1002/pon.1593.

41. Salgado TM, Davis EJ, Farris KB, Fawaz S, Batra P, Henry NL. Identifying socio-demographic and clinical characteristics associated with medication beliefs about aromatase inhibitors among postmenopausal women with breast cancer. Breast Cancer Res Treat. 2017; 163:311-19. https://doi.org/10.1007/s10549-017-4177-9.

42. Cooper C, Carpenter I, Katona C, Schroll M, Wagner C, Fialova D, Livingston G. The AdHOC Study of older adults' adherence to medication in 11 countries. Am J Geriatr Psychiatry. 2005; 13:1067-76. https://doi. org/10.1097/00019442-200512000-00006.

43. Wade B, Bowling A. Appropriate use of drugs by elderly people. J Adv Nurs. 1986; 11:47-55. https://doi. org/10.1111/j.1365-2648.1986.tb01219.x.

44. Fink AK, Gurwitz J, Rakowski W, Guadagnoli E, Silliman RA. Patient beliefs and tamoxifen discontinuance in older women with estrogen receptor-positive breast cancer. J Clin Oncol. 2004; 22:3309-15. https://doi.org/10.1200/ JCO.2004.11.064.

45. Grunfeld EA, Hunter MS, Sikka P, Mittal S. Adherence beliefs among breast cancer patients taking tamoxifen. Patient Educ Couns. 2005; 59:97-102. https://doi. org/10.1016/j.pec.2004.10.005.

46. Neugut AI, Hillyer GC, Kushi LH, Lamerato L, Leoce N, Nathanson SD, Ambrosone CB, Bovbjerg DH, Mandelblatt JS, Magai C, Tsai WY, Jacobson JS, Hershman DL. Noninitiation of adjuvant hormonal therapy in women with hormone receptor-positive breast cancer: The Breast Cancer Quality of Care Study (BQUAL). Breast Cancer Res Treat. 2012; 134:419-28. https://doi.org/10.1007/s10549-0122066-9. 
47. Atkins L, Fallowfield L. Intentional and non-intentional non-adherence to medication amongst breast cancer patients. Eur J Cancer. 2006; 42:2271-76. https://doi. org/10.1016/j.ejca.2006.03.004.

48. Garreau JR, Delamelena T, Walts D, Karamlou K, Johnson N. Side effects of aromatase inhibitors versus tamoxifen: the patients' perspective. Am J Surg. 2006; 192:496-98. https://doi.org/10.1016/j.amjsurg.2006.06.018.

49. Owusu C, Buist DS, Field TS, Lash TL, Thwin SS, Geiger AM, Quinn VP, Frost F, Prout M, Yood MU, Wei F, Silliman RA. Predictors of tamoxifen discontinuation among older women with estrogen receptor-positive breast cancer. J Clin Oncol. 2008; 26:549-55. https://doi.org/10.1200/ JCO.2006.10.1022
50. Kahn KL, Schneider EC, Malin JL, Adams JL, Epstein AM. Patient centered experiences in breast cancer: predicting long-term adherence to tamoxifen use. Med Care. 2007; 45:431-39. https://doi.org/10.1097/01. mlr.0000257193.10760.7f

51. Rydén L, Heibert Arnlind M, Vitols S, Höistad M, Ahlgren J. Aromatase inhibitors alone or sequentially combined with tamoxifen in postmenopausal early breast cancer compared with tamoxifen or placebo - Meta-analyses on efficacy and adverse events based on randomized clinical trials. Breast. 2016; 26:106-14. https://doi.org/10.1016/j. breast.2016.01.006. 